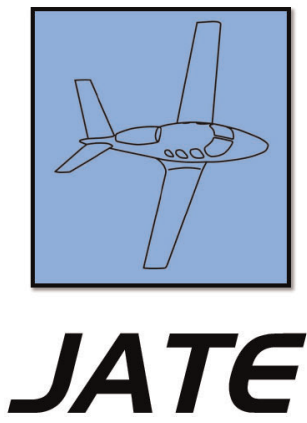

Journal of Aviation Technology and Engineering 6:2 (2017) 26-32

\title{
A Comparison of Malfunction-Related Accidents for General Aviation Aircraft Manufactured in 1970-1984 and 2000-2014
}

\author{
Douglas Boyd \\ University of Texas Graduate School of Biomedical Sciences at Houston \\ Jochen Hinkelbein \\ Department of Anesthesiology and Intensive Care Medicine, University Hospital of Cologne
}

\begin{abstract}
The United States general aviation fleet is aging with aircraft manufactured 35-39 years ago representing the most prevalent group. Since older aircraft are more prone to airframe corrosion, fatigue, and brittle electrical wiring, the present study was undertaken to determine whether malfunction-related accidents for general aviation aircraft manufactured between 1970 and 1984 were elevated relative to airplanes produced more recently (2000-2014).

The NTSB aviation accident database was used to identify piston-powered airplane accidents occurring over the 2005-2014 period. Aircraft manufacture year and fleet activity data were from the FAA. Statistical analyses employed contingency tables and Poisson distributions.

The proportion of malfunction-related accidents was unchanged ( $p=0.219)$ for aircraft manufactured over the two periods (12.2\%, 2005-2014; 14.3\%, 1970-1984). Similarly, malfunction-related accident rates for aircraft of older and more recent vintage were comparable: 2.73 and 2.63 per 100,000 flight hours $(p=0.866)$. The proportion of accidents related to airframe/flight control or electrical system failures between both aircraft cohorts was statistically insignificant $(p=0.139)$. Malfunction-related accidents for airplanes of recent production were more likely $(p<0.001)$ due to manufacture deficiencies, whereas mishaps with airplanes of earlier vintage were more probably a consequence of maintenance deficiencies. Despite the fact that $>90 \%$ of aircraft in both production eras were substantially damaged/destroyed, the overwhelming majority (70-71\%) of accidents involved no occupant injuries.

This study suggests that aircraft of 35-39 years of age do not carry excess risk for malfunction-related accidents in comparison with aircraft of more recent manufacture. Presumably, these findings largely reflect the success of current inspection/maintenance practices.
\end{abstract}

Keywords: general aviation, aging aircraft, aviation accidents, malfunction, maintenance, accident, crash

\section{Introduction}

A clear problem posed to aviation safety in the United States relates to the aging general aviation fleet. Indeed, as of 2014, general aviation aircraft manufactured 35-39 years ago represented the most prevalent age group for the entire fleet of 
piston-powered airplanes (FAA, 2015). Older aircraft are, not surprisingly, more prone to airframe corrosion, fatigue, and brittle electrical wiring (Nelson \& Drews, 2008). Such situations could adversely impact flight safety, and have in the past. For example, in 1988 undetected airframe corrosion and fatigue damage led to an explosive decompression of a high airframe hour $(35,496)$ Boeing 737 en route from Hilo to Honolulu, Hawaii (National Transportation Safety Board (NTSB) accident \#DCA88MA054). Nearly two decades later, in 2005, the right wing of a Grumman Mallard amphibious airplane manufactured in 1947 separated from the fuselage shortly after takeoff, and all onboard were lost (NTSB accident \#DCA06MA010). The latter accident was attributed, in part, to fatigue cracks in the right wing. Aging also leads to deterioration in electrical wiring. Frayed wiring, or wiring denuded of its insulation, may lead to an electrical failure with the potential loss of radio communications, navigational instruments, and retrofitted electronic flight displays. In a worst-case scenario, wire deterioration could culminate in an in-flight fire.

Mandatory (annual or 100-hour) inspections of general aviation aircraft do not differ based on airplane age (FAA, 2008). However, a consortium of aviation organizations, airplane manufacturers, and the Federal Aviation Agency (FAA) has questioned whether current inspection protocols (specified per the Code of Federal Regulations (CFR)14CFR43.15) are sufficient for maintaining aging general aviation aircraft. Indeed, this consortium advanced an additional set of tasks for inspections of such aircraft. These recommendations were, however, advisory rather than mandatory in nature (FAA, 2003). Moreover, the aforementioned tasks still relied on visual inspection leaving open the possibility that subsurface corrosion and/or fissures could escape detection. Such deficiencies can indeed be detected by a variety of techniques (e.g., acoustic emission, radiography, and ultrasonic techniques) and methods that are currently employed for transport-category aircraft inspections (FAA, 2008). However such techniques were not included in the recommendations by the consortium (presumably due to the cost burden of additional equipment and trained personnel).

Per a literature review, there is little published material on malfunction-related accidents associated with advancing age of the general aviation fleet. Nelson and Drews (2008), using airframe hours as a surrogate for airplane age, reported that these types of accidents increased with airframe hours for single-piston engine powered aircraft across the 19821988 period. However, the lack of denominator data precluded any adjustment for the varying number of hours flown for aircraft of different airframe times. In addition, an aircraft which has, at some point, been used for training may have accumulated high airframe hours yet also be of a modest chronological age.

With these aforementioned considerations in mind, the purpose/research question of the study herein was to determine if older general aviation aircraft (manufactured 1970-1984) fared worse in terms of the rate and types of malfunctionrelated accidents compared to aircraft of more recent vintage (manufactured 2000-2014).

\section{Methods}

\section{Query Strategy and Data Sources}

The publicly available NTSB aviation accident Microsoft ${ }^{\circledR}$ Access database (2016 March release) (NTSB, 2015a) was downloaded and queried for accident/incident data as described below. Despite its name, this database is inclusive of both accidents and incidents (see definition per e-CFR, 2010). Data on the year of aircraft manufacture was obtained from the FAA (2016) and imported into the aforementioned NTSB database. Accident/incident records without a year of manufacture were deleted from the study.

The database was queried for accidents or incidents occurring over the 2005-2014 period in piston-powered airplanes $(<12,501 \mathrm{lbs}$.) manufactured either in the years spanning 1970-1984 or 2000-2014 (unless specified otherwise) and operating under general aviation regulations per 14CFR91. Hereafter, the term "accidents" refers to mishaps inclusive of accidents and incidents. Accidents in homebuilt aircraft were excluded from the study since construction quality varies and these airplanes are exempt from the design standards specified per 14CFR Part 23 for general aviation (e-CFR, 2012). Data were exported to Excel, and conditional formatting was used to verify the absence of duplicate records.

Malfunction-related accidents were identified by manual inspection of the NTSB narrative cause and categorized per Table 1. For malfunction-related mishaps, the following accidents were excluded: (a) where a landing gear failure was secondary to hard landing; (b) those for which the cause of the malfunction could not be determined; (c) where the aircraft was operated outside of its performance envelope (e.g. never exceed, $\mathrm{V}_{\mathrm{NE}}$, or maneuvering speeds, $\mathrm{V}_{\mathrm{A}}$ ); (d) aircraft operated with a known deficiency or for which service bulletins, airworthiness directives, or maintenance schedule (including prescribed times for engine overhaul) had not been complied with.

Injury severity was per the NTSB report, the latter using strict criteria for each category (NTSB Form 6120.1; e-CFR, 2010; NTSB, 2015b). Thus, fatal injury was one

Table 1

Variables used.

Malfunction Category

Airframe/Flight Controls

Electrical

Fuel-Oil

Landing Gear/Brakes

Propulsion

Other (avionics, air conditioning) 
that resulted in death within thirty days of the accident. Serious injury referred to one that (a) required hospitalization for more than 48 hours, commencing within seven days from the injury date; (b) resulted in a bone fraction; (c) caused severe hemorrhage, nerve, muscle or tendon damage; (d) involved injury to any internal organ; or (e) involved second- or third-degree burns or any burns that affected more than $5 \%$ of the body surface. Minor injury was any that did not meet the criteria for another injury severity. Similarly, the severity of aircraft damage was per the NTSB report, again using specific criteria defined in 49CFR830.2 (e-CFR, 2010; NTSB, 2015b). Substantial damage referred to damage or failure that adversely affected the aircraft structural strength, performance, or flight characteristics.

Fleet activity for aircraft cohorts manufactured in 19701984 and 2000-2004 was derived from the FAA General Aviation and Part 135 Activity Surveys (FAA, 2015). For each manufacture cohort, fleet activity represented the average annual fleet time (hours) across the accident capture period (2005-2014) corresponding to fixed-wing piston enginepowered aircraft.

\section{Statistics}

Proportion tests employed Pearson chi-square, unless the expected count was less than five, whereby Fisher's Exact Test was used (Field, 2009) to determine if there was an overall difference in proportions. To determine the contribution of cells in multinomial tables to an overall difference in proportions, $p$ values were derived from adjusted standardized residuals (Z-scores) in post-hoc testing. To determine whether the rate of malfunction-related accidents differed for aircraft manufactured at different times, a generalized linear model with Poisson distribution was employed using the natural $\log$ of the fleet hours for each manufacture cohort as an offset. IBM SPSS (v 23) software was used for all statistical analyses. A $p$ value of $<0.05$ was considered statistically significant.

\section{Results}

For aircraft manufactured during the 1970-1984 and 2000-2014 periods, 1,192 and 743 accidents (inclusive of malfunction-related/unrelated mishaps occurring over the decade spanning 2005-2014) were identified from the NTSB database, respectively.

\section{Comparison of Malfunction-Related Accidents for Aircraft of New and Old Manufacture}

To determine if aircraft of older vintage carried an excess risk for malfunction-related accidents, we asked two questions: First, was the proportion of malfunction-related accidents elevated for older aircraft? Second, was the rate of malfunction-related mishaps higher for these aircraft?
Regarding the first question, for aircraft of 30-44 years of age, $14.3 \%$ of accidents occurring over the 2005-2014 period were malfunction-related (Figure 1A). Similarly, $12.2 \%$ of accidents over the corresponding period were malfunction-related for aircraft manufactured over the last 14 years (Figure 1A). Using a chi-square test, the difference in proportions of malfunction-related accidents between the two manufacture periods was statistically insignificant $(p=$ 0.219 ). For the second enquiry, the rate of these types of accidents occurring over the decade spanning 2005-2014 was compared for the two aircraft cohorts. The denominator data used for rate determination was fleet activity for fixed-wing piston engine-powered aircraft for the
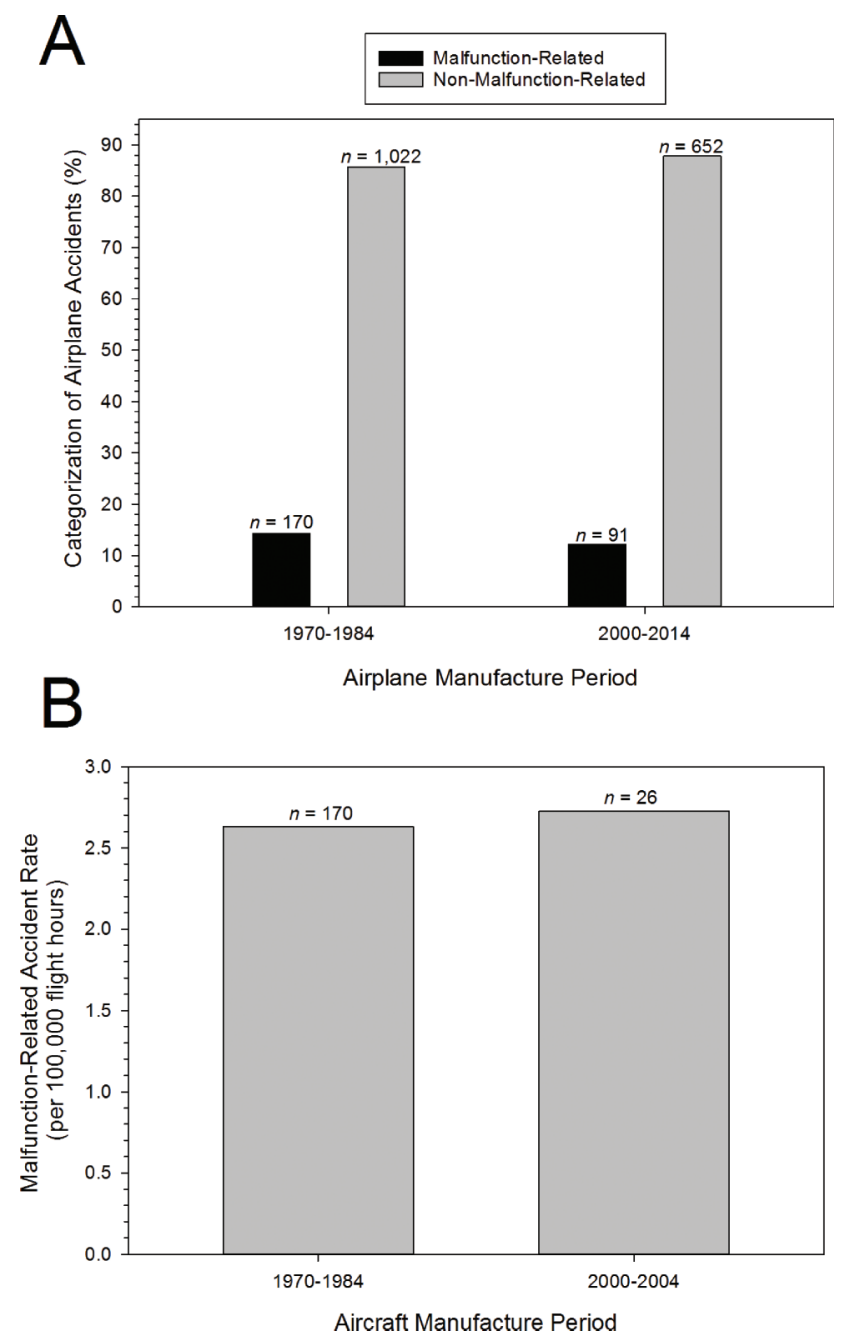

Figure 1. Malfunction-related accidents for aircraft of recent and older manufacture. Aircraft accidents occurring over the period spanning 20052014 were categorized as related or unrelated to a systems malfunction for the specified period of airplane manufacture. Panel A: These categories were expressed as a percentage of all (sum of malfunction-related and non-related) accidents for the specified period ( $n$, number of accidents). Panel B: The rate (accident count adjusted for flight hours) of malfunctionrelated accidents for the indicated period of aircraft manufacture is shown ( $n$, number of accidents). Proportion testing for Panel A used a $2 \times 2$ contingency table and a chi-square test. For Panel B, a Poisson distribution was used for statistical analysis. 
corresponding manufacture period. To assure comparable risk exposure for newly manufactured and older vintage aircraft, accident counts for the former cohort were restricted to those aircraft produced between 2000 and 2004 (Figure 1B). The rates of malfunction-related accidents for both groups were comparable: 2.73 and 2.63 (per 100,000 flight hours) for the two cohorts, respectively. A Poisson distribution analysis testing for differences in malfunction-related accident rate indicated this difference to be statistically insignificant $(p=0.866)$. Taken together these data argue against the notion that older aircraft are more likely to experience malfunction-related accidents.

\section{Comparison of Systems Failures in Aircraft of New and Older Manufacture}

Malfunction-related accidents were then subcategorized to determine if there was any difference in system failures between aircraft manufactured over the two separate periods (Figure 2). For increased statistical power, we combined some of the systems failures. Using a chi-square test, a nonstatistical $(p=0.139)$ trend for an increase in the proportion of accidents related to airframe/flight control failures was evident for aircraft of newer vintage (manufactured 2000-2014).

Noteworthy, despite the increased potential for electrical wire deterioration in aging aircraft, the fraction of accidents

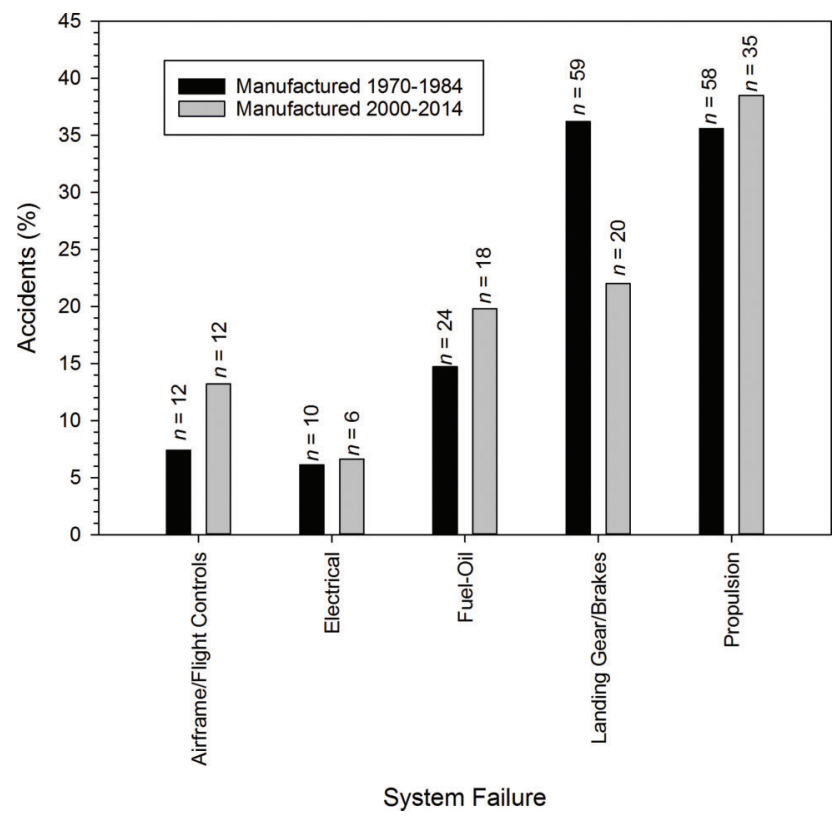

Figure 2. System failures in aircraft of new and older manufacture. Malfunction-related accidents were subcategorized by system failure with the exception of the "other category." The number of accidents $(n)$ for a specified systems failure was expressed as a percentage of all malfunctionrelated accidents for the indicated airplane manufacture period. A chisquare test was used to determine if an overall difference in proportions of systems failures existed between the two different aircraft manufacture periods. related to electrical system malfunctions in airplanes manufactured over the 1970-1984 period was statistically unchanged (using a chi-square test) to those of more recent production.

\section{Categorization of Malfunction-Related Accidents by Deficiencies in Manufacture and Maintenance}

We then determined if malfunction-related accidents for aircraft manufactured over the two separate periods were caused by deficiencies in maintenance, manufacture, or unrelated to either. Of the malfunction-related accidents, 80 aircraft manufactured 2000-2014 and 137 aircraft produced 1970-1984 could be categorized based on the NTSB data available. The largest proportion (64 and 56\% for aircraft of older and newer vintage, respectively) of accidents, however, was neither caused by manufacture nor maintenance deficiencies (Figure 3), and this difference was not significant ( $p=0.271)$ in post-hoc testing using adjusted standardized residuals ( $Z$-scores). Conversely, based on adjusted standardized residuals, aircraft produced between 1970 and 1984 were underrepresented $(p<0.001)$ for manufacturing deficiency-related accidents relative (Figure 3 ) to those airplanes of more recent vintage $(<1$ and $16 \%$, respectively).

\section{Severity and Occupant Injury for Aircraft of Older and Newer Vintage}

The potential for metal fatigue with aging aircraft raised the possibility that aircraft damage severity would be

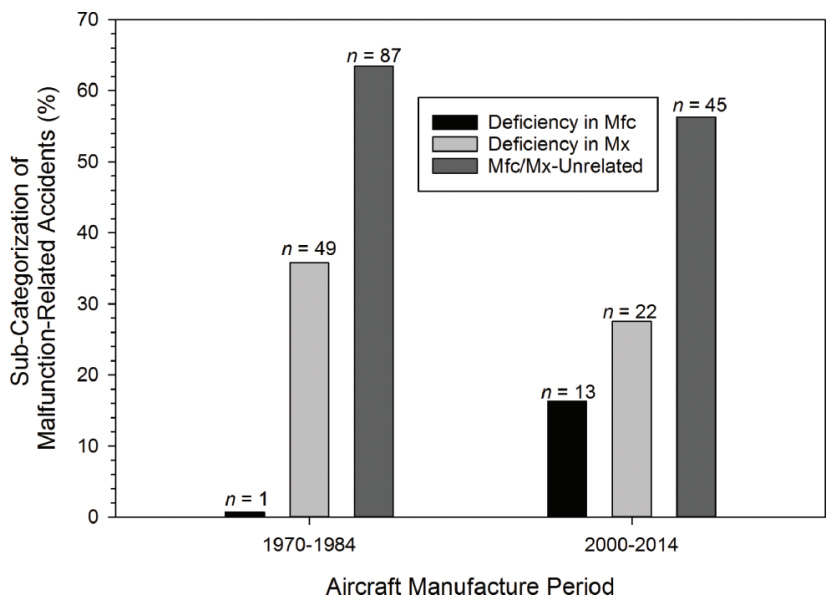

Figure 3. Categorization of malfunction-related accidents by deficiencies in manufacture and maintenance. Malfunction-related accidents were subcategorized as due to deficiencies in manufacture (Deficiency in $\mathrm{Mfc}$ ), maintenance (Deficiency in Mx), or unrelated to either (Mfc/ Mx-Unrelated). These data are expressed as a percentage of the total number of malfunction-related accidents (which could be categorized) for the specified period of aircraft manufacture ( $n$, accident count). A $2 \times 3$ contingency table indicated an overall difference in proportions between the two production era aircraft groups $(p<0.001)$. 


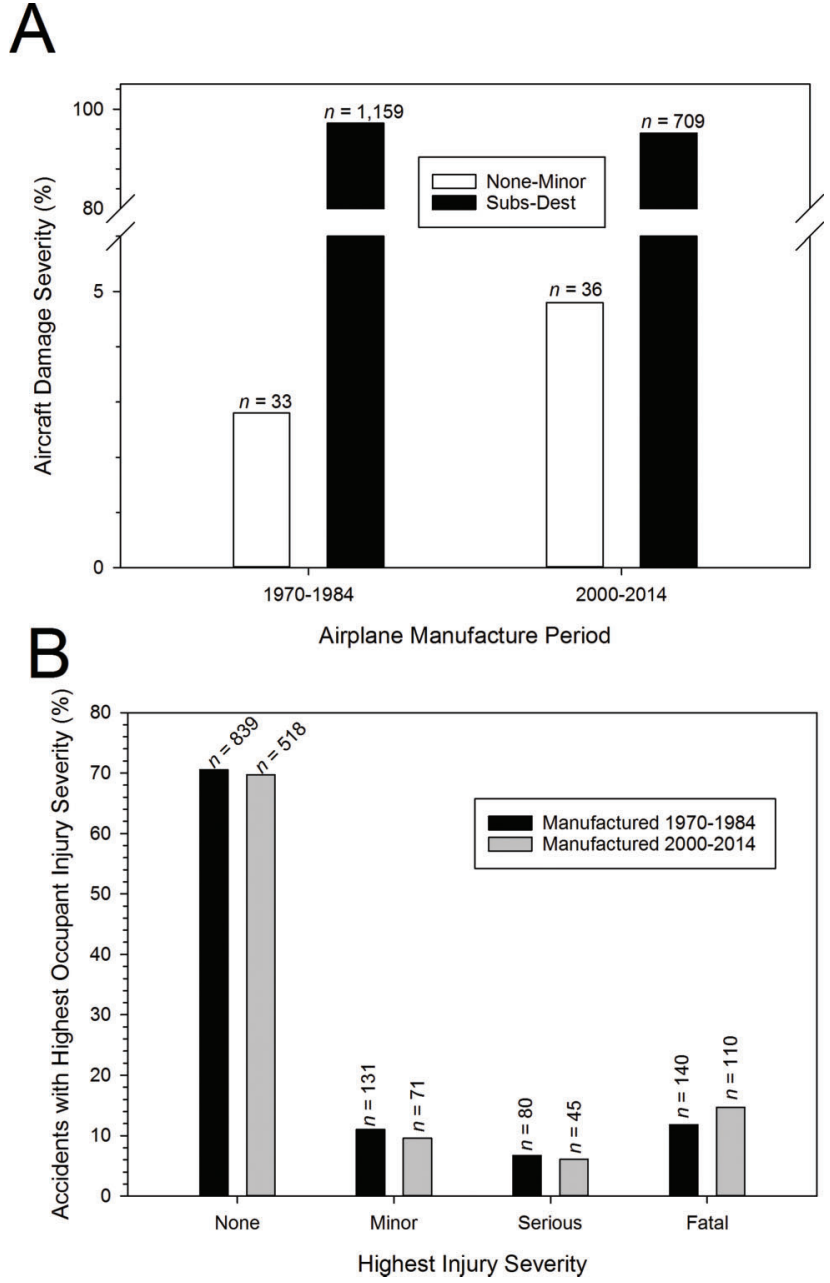

Figure 4. Damage severity and occupant injury for aircraft manufactured in the periods spanning 1970-1984 and 2000-2014. Panel A: Aircraft damage for accidents (malfunction-related and non-malfunction-related combined) in airplanes produced over the indicated period was categorized as either none-minor or substantial-destroyed (Subs/Dest) per the NTSB report. Accident damage severity (ordinate) is expressed as a percentage of the sum of counts in both categories for the specified aircraft manufacture period. Panel B: The percentage of accidents (inclusive of malfunctionrelated and non-malfunction-related mishaps) with the indicated highest occupant injury (none, minor, serious, fatal) is shown for the specified aircraft manufacture period. Statistical testing for overall differences was determined using a $2 \times 4$ contingency table ( $n$, accident count).

greater for accident airplanes manufactured over the earlier period. For increased statistical power, and because this question did not pertain to malfunction-related accidents, the database query was extended to include accidents which were unrelated to a failed system. However, both aircraft cohorts showed (Figure 4A) a high and comparable proportion (97 and 95\% for aircraft manufactured 1970-1984 and 2000-2014, respectively) of airplanes that received substantial damage or were destroyed in the accident.

Occupant injury severity was then determined for aircraft manufactured over the two independent periods. Interestingly, despite the fact that $>90 \%$ of aircraft received substantial damage or were destroyed irrespective of manufacture period, the overwhelming majority of accidents involved no occupant injuries. Thus, there were no injuries for 71 and $70 \%$ of accidents for aircraft manufactured over 1970-1985 and 2000-2014, respectively (Figure 4B). The proportion of accidents across the various occupant injury severities, when comparing the two aircraft cohorts, was statistically unchanged as determined by a chi-square analysis $(p=0.234)$.

\section{Discussion}

The study herein provides evidence that properly maintained aircraft of 30-44 years' chronological age are comparable in safety to aircraft of more recent production (manufactured within the last 14 years). Thus, malfunctionrelated accidents were not disproportionately higher for older aircraft, and the accident rate for these types of mishaps was statistically identical relative to airplanes of more recent manufacture. Importantly, the proportion of accidents related to airframe fatigue or electrical failures, two systems which would be most vulnerable to the passage of time (FAA, 2003; Nelson \& Drews, 2008), were no higher than for aircraft of more recent manufacture. Taken together, these findings would suggest that maintenance practices, in current usage, are identifying and correcting deficiencies, thus warding off potential accidents relating to aircraft age. Indeed, our findings resonate with a recent study (Boyd \& Stolzer, 2015) reporting a low general aviation accident rate related to maintenance deficiencies.

Our findings were divergent with a separate investigation (Nelson \& Drews, 2008) in which an increase in airframe hours for single-engine piston aircraft was associated with a higher mechanical-related accident count. However, there were notable differences between both studies. Perhaps most relevant, the prior study (Nelson \& Drews, 2008) did not adjust the accident count for varying flight time for the aircraft of differing airframe times. For example, if aircraft of higher airframe hours are flown more often during the accident capture period specified for the study, their risk exposure would increase. Another possible explanation for the divergent results could lie in the use of airframe hours as a metric of chronological aircraft age for the prior study. An aircraft that, at some point, has been used for flight training may have accumulated a high number of airframe hours, yet it may still be chronologically "young." Finally, the accident capture period utilized for the prior report (1982-1988) preceded ours by a good two decades (20052014).

Of interest was the observation that, for malfunctionrelated accidents, aircraft from different manufacture eras showed a disparity between manufacturing and maintenance deficiencies. Thus, accidents for airplanes of recent production (2000-2014), whose manufacture was invigorated by the "General Aviation Revitalization Act of 1994" (Public Law 103-298), were more likely $(p<0.001)$ due to 
manufacture deficiencies. In contrast, mishaps with airplanes of earlier vintage (1970-1984) were more probably a consequence of maintenance deficiencies. Perhaps of greater importance was that accidents unrelated to either manufacture or maintenance deficiencies represented the largest proportions for aircraft in both production cohorts. For the large part, such malfunctions, comparable in proportions for both aircraft cohorts, represented unexpected failures inherent to any mechanical system.

The high proportion $(>90 \%)$ of aircraft in both manufacture cohorts that were either substantially damaged or were destroyed deserves discussion. This skewing of the data (with few aircraft receiving no or minor damage) likely reflects mishap-reporting criteria (e-CFR, 2010). Thus, reporting is required for only those events in which an occupant suffers death or serious injury, or in which the aircraft receives substantial damage. The latter is defined as damage or failure adversely affecting the structural strength, performance, or flight characteristics of the aircraft. Conversely, engine failure and damage to the landing gear, flaps, engine accessories, brakes, or wingtips are excluded, and such events do not necessitate a report (e-CFR, 2010). Thus, a subset of malfunction-related mishaps in which only the latter criteria are satisfied would be absent from the NTSB accident database used in the present study.

The proportion of accidents involving fatal injuries for both cohorts (12-15\%) was comparable to the $14 \%$ cited in a prior study on German general aviation accidents involving piston-powered airplanes under two tons (Neuhaus et al., 2010). However, more importantly, the finding of comparable occupant injury severity for the aircraft cohorts from different manufacture periods was initially surprising. This was unexpected since a subset of aircraft of recent design and manufacture (Cirrus and Lancair) have to be in compliance with more stringent crashworthiness standards for occupant protection (DeHaven, 2002). The more rigorous testing includes multi-axis dynamic tests using an anthropomorphic dummy and higher G-loads (more typical of a crash event), and takes into account floor warpage per 14CFR 23.562 (e-CFR, 2016). Indeed, a recent report demonstrated the efficacy of these improved standards in mitigating injury severity (Boyd, 2015). Why then did these improved standards not translate into reduced injury severity for aircraft of recent manufacture? The answer reflects, in part, the fact that aircraft of an older design, but still in current manufacture, are not subject to these new standards. Indeed, only a small fraction $(\sim 11 \%)$ of accident aircraft manufactured during the 2000-2014 period were built to the higher crashworthiness standards.

Our study was not without limitations. First, it was a retrospective study. Second, and as discussed above, system failures for the aging fleet may be underestimated for the following reason. Unless the failure resulted in a mishap that mandated reporting to the NTSB (e-CFR, 2010), the event would not be captured for the accident database used for the current enquiry.

\section{Conclusion}

The study herein strongly suggests that, despite the potential for aircraft system deterioration with advancing age, maintenance practices in current usage are keeping an aging aircraft fleet as safe as aircraft of more recent manufacture. What is unclear at the present time, and worthy of future study, is the contribution of maintenance practices, advocated (but not mandatory) by a consortium of manufacturers, organizations, and the FAA (2003) for the aging general aviation fleet, to the level of safety witnessed in the current study.

\section{References}

Boyd, D. D. (2015). Occupant injury and fatality in general aviation aircraft for which dynamic crash testing is certification-mandated. Accident Analysis and Prevention, 79, 182-189.

Boyd, D. D., \& Stolzer, A. (2015). Causes and trends in maintenancerelated accidents in FAA-certified single engine piston aircraft. JATE $5(1), 17-24$.

DeHaven, H. (2002). Small airplane crashworthiness design guide (RF AGATE-WP3.4-034043-036; eds. T. R. Hurley and J. M. Vandenburg; chapter 1, pp. 5-9). Pheonix, AZ: Simula Technologies.

Electronic Code of Federal Regulation (e-CFR). (2010). Transportation: Notification and reporting of aircraft accidents or incidents and overdue aircraft, and preservation of aircraft wreckage, mail, cargo and records. 49 CFR 830. http://www.ecfr.gov/cgi-bin/text-idx?tpl=/ecfrbrowse/ Title49/49cfr830_main_02.tpl

Electronic Code of Federal Regulation (e-CFR). (2012). Airworthiness standards: Normal, utility, acrobatic and commuter category airplanes. http://www.ecfr.gov/cgi-bin/text-idx ?SID = 5ffea7e4489b0113fefc117f 1b9fc96a\&mc $=$ true \&node $=$ pt14.1.23\&rgn $=$ div5 \#se14.1.23_11

Electronic Code of Federal Regulation (e-CFR). (2016). Emergency landing conditions. http://www.ecfr.gov/cgi-bin/text-idx?SID= eb5c2484236928b8e80e743d2b5528e3\&mc $=$ true \&node $=$ pt14.1.23\& $\operatorname{rgn}=\operatorname{div} 5$

Federal Aviation Administration (FAA). (2003). Best practices guide for maintaining aging general aviation airplanes. http://www.faa.gov/ aircraft/air_cert/design_approvals/small_airplanes/cos/aging_aircraft/ media/aging_air_booklet.pdf

Federal Aviation Administration (FAA). (2008). Inspection fundamentals. In Aviation maintenance technician handbook (FAA-H-8083-30) (pp. 1-34). Oklahoma City: United States Department of Transportation, Federal Aviaton Administration.

Federal Aviation Administration (FAA). (2015). General aviation and part 135 activity surveys. http://www.faa.gov/data_research/aviation data_statistics/general_aviation

Federal Aviation Administration (FAA). (2016). Aircraft registry. http:// www.faa.gov/licenses_certificates/aircraft_certification/aircraft_ registry/releasable_aircraft_download

Field, A. (2009). Discovering statistics using IBM SPSS statistics. Thousand Oaks, CA: SAGE.

National Transportation Safety Board (NTSB). (2015a). NTSB accident database. http://app.ntsb.gov/avdata/Access/ 
National Transportation Safety Board (NTSB). (2015b). Pilot/operator Aircraft accident/incident report. http://www.ntsb.gov/Documents/ 6120_1web_nopwx_NotReaderComp.pdf

Nelson, R. A. and Drews, J. N. (2008). Strict product liability and safety: Evidence from the general aviation market. Economic Enquiry, 46(3), $425-437$.

Neuhaus, C., Dambier, M., Glaser, E., Schwalbe, M., \& Hinkelbein, J. (2010). Probabilities for severe and fatal injuries in general aviation accidents. Journal of Aircraft, 47(6), 2017-2020.
Douglas Boyd, $\mathrm{PhD}$, professor at the University of Texas, is an active commercial pilot in single- and multiengine aircraft, and is IFR-certified and type-rated in a Citation 500. His current projects and interests focus on the causes of general aviation accidents.

Jochen Hinkelbein, MD, professor of anesthesiology at the University Hospital of Cologne, is a certified commercial pilot in fixed-wing aircraft and vice president of the German Society of Aerospace Medicine (DGLRM). His research interests include helicopter emergency medical services safety, emergency medicine, and in-flight medical emergencies. 